\title{
Available energy from soft drinks: more than the sum of its parts
}

\author{
Anwar T Merchant ${ }^{1, *}$, Avnish Tripathi ${ }^{1}$ and Farhan Pervaiz ${ }^{2}$ \\ 'Department of Epidemiology and Biostatistics, Arnold School of Public Health, University of South Carolina, \\ 800 Sumter Street, Columbia, SC 29208, USA: ${ }^{2}$ Faculty of Health Sciences, McMaster University, Hamilton, \\ Ontario, Canada
}

Submitted 11 September 2009: Accepted 24 March 2010: First published online 6 May 2010

\begin{abstract}
Objective: To evaluate the relationship between energy available from sugarsweetened beverages (SSB) and total energy availability.

Design: Ecological study using food availability data from 1976 to 2007 from the database of the Canadian Socio-Economic Information Management System. The average available total daily energy per capita ( $\mathrm{kJ}(\mathrm{kcal}) / \mathrm{d}$ per capita) and percentage of energy from SSB (\%E/d per capita) were calculated. A regression analysis was performed with average available total daily energy per capita $(\mathrm{kJ}$ (kcal)/d per capita) as the outcome and percentage of energy from SSB as the independent variable (\%E/d per capita).

Setting: Canada 1976-2007.

Subjects: None.

Results: Between 1976 and 2007, total available energy increased on average by $669 \mathrm{~kJ}(160 \mathrm{kcal}) / \mathrm{d}$ per capita, and energy from SSB by $155 \mathrm{~kJ}(37 \mathrm{kcal}) / \mathrm{d}$ per capita. Total available energy increased by $434 \mathrm{~kJ}(104 \mathrm{kcal}) / \mathrm{d}$ per capita for a one unit increase in average percentage of energy from SSB.

Conclusions: Total available energy increased as the contribution of energy available from SSB increased. This increase was larger than that explained by energy availability from SSB alone. Reducing energy from soft drinks may contribute to larger reductions in total energy available for consumption.
\end{abstract}

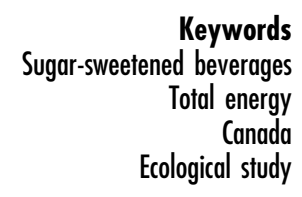

Sugar-sweetened beverages (SSB) contribute to weight gain and poor health. Reducing SSB consumption in randomised controlled trials decreases energy intake and $\mathrm{BMI}^{(1)}$. SSB consumption is positively associated with energy consumption, weight gain, overweight and obesity, and type-2 diabetes ${ }^{(2,3)}$. Levying a tax on SSB has been proposed as a strategy to reduce their consumption, and thereby reduce energy intake and ultimately obesity ${ }^{(4)}$. SSB consumption displaces healthy dietary elements and leads to poor diet quality, and decreasing SSB consumption reduces overall energy intake ${ }^{(5,6)}$. We evaluated the relationship between energy availability from SSB and total energy availability from food availability data in Canada collected over 30 years.

\section{Methods}

\section{Data source}

The Canadian Socio-Economic Information Management System (CANSIM) is Statistics Canada's computerised database of time series covering a wide area of the social and economic aspects of Canadian life ${ }^{(7)}$. The CANSIM database includes information on a variety of topics such as national accounts, labour, manufacturing, construction, trade, agriculture and finance. Food availability information in the CANSIM database is based on food disappearance and accounts for wastage in production and storage. The data are not the energy consumed and do not account for wastage in the home. Data from 1976 to 2007 were used in these analyses ${ }^{(7)}$.

\section{Energy availability}

Energy availability is obtained by multiplying the quantity of a food by its unit energy content. For instance, the total available servings of ice cream in a year are multiplied by the energy content of one serving. Total available energy is obtained by summing the available energy over all available foods. Average daily per capita available energy is determined by dividing the total available daily energy in any year by 365 and the estimated Canadian population on 1 July of that year.

\section{Soft drinks}

Information on sugar-sweetened soft drink availability in CANSIM is obtained from total domestic sales, as provided by the Canadian Soft Drink Association. The information collected for sugar-sweetened soft drink 
availability includes the energy content and volume sold in Canada in any year. Average daily per capita available energy from sugar-sweetened soft drinks is determined by dividing the total available daily energy in any year by the estimated Canadian population on 1 July of that year. Average percentage of energy from sugar-sweetened soft drinks is obtained by dividing the average daily per capita available energy from soft drinks by the average daily per capita energy for each year.

\section{Juices}

Information on grapefruit, grape, lemon, orange and pineapple juice availability is obtained from the import and export data available from the International Trade Division of Statistics Canada. In the case of apple and tomato juices, information on production and stocks is available from the Manufacturing, Construction and Energy Division of Statistics Canada.

\section{Alcobolic beverages}

Estimates of availability were made from sales data provided by the Canadian Brewers' Association for beer, by the Association of Distillers for liquor and by the Canadian Wine Institute for wine. Data based on sales from the Public Institutions Division of Statistics Canada were used to update these preliminary figures.

\section{Statistical metbods}

Average daily per capita available energy and average percentage of energy from sugar-sweetened soft drinks were computed. Average daily per capita available energy was plotted against the average percentage of energy from sugar-sweetened soft drinks in a scatter plot. A regression line was fitted with the average daily per capita available energy as the outcome and average percentage of energy from soft drinks as the predictor. SAS statistical software package version $9 \cdot 0$ (SAS Institute Inc., Cary, NC, USA) was used in the analysis.

\section{Results}

In 2007, the total available energy in Canada was $10157 \mathrm{~kJ}$ $(2429 \mathrm{kcal}) / \mathrm{d}$ per capita, of which approximately 13\% (1342 kJ (321 kcal)/d per capita) came from beverages and $4 \cdot 6 \%$ ( $464 \mathrm{~kJ}(111 \mathrm{kcal}) / \mathrm{d}$ per capita) from SSB. Between 1976 and 2007, there was an increase of $669 \mathrm{~kJ}(160 \mathrm{kcal}) / \mathrm{d}$ per capita in available energy, with $155 \mathrm{~kJ}$ (37 kcal)/d per capita in available energy from SSB and $59 \mathrm{~kJ}(14 \mathrm{kcal}) / \mathrm{d}$ per capita in available energy from juices.

There was a positive linear association between average total available energy and average percentage of energy from SSB. Total available energy was increased by $434 \mathrm{~kJ}(104 \mathrm{kcal}) / \mathrm{d}$ per capita for a one unit increase in average percentage of energy from SSB (Fig. 1).

\section{Discussion}

Total available energy increased as the contribution of energy available from SSB increased. This increase was larger than that explained by energy availability from SSB alone. There are at least two plausible explanations for this finding. First, soft drinks are a marker of consumption of high-energy foods ${ }^{(8)}$. US adults who ate fast foods consumed twice as much energy from SSB and 15-22\% more energy overall ${ }^{(8)}$. Replacing SSB with diet beverages would still result in excess energy intake if this mechanism operated. Second, energy provided by SSB does not compensate for subsequent energy intake ${ }^{(9)}$. This is consistent with the results of a crossover trial with ad libitum food consumption in which daily energy intake declined by $1629 \mathrm{~kJ}(389 \mathrm{kcal})$ in the group with less $\mathrm{SSB}^{(6)}$. We can hypothesise, therefore, that reducing the energy available from SSB will reduce total available energy beyond that explained by SSB.

A limitation in the data of the present study is that energy availability is an ecological variable. The two main

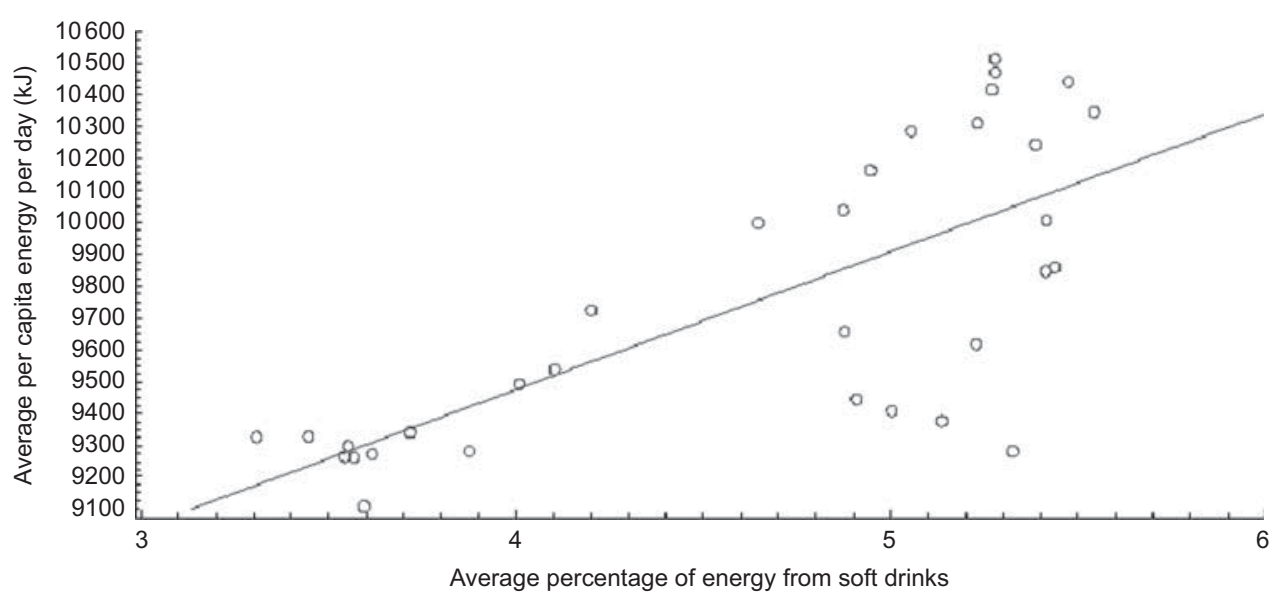

Fig. 1 Relationship between average per capita daily energy availability and percentage of energy (\%E) from soft drinks (regression equation: average daily per capita energy $=7740+434 \times$ average $\%$ from soft drinks) 
drawbacks of using ecological data are: (i) they could represent a characteristic of the environment not causally related to the outcome of interest; and (ii) they are aggregated at the community level, and do not represent individual behaviour. There are strong data indicating that SSB consumption increases overall energy intake and weight gain $^{(10)}$. In a randomised control trial study, Chen et $\mathrm{l}^{(11)}$ showed that a $418 \mathrm{~kJ}$ (100 kcal) reduction in liquid energy resulted in a $0 \cdot 25 \mathrm{~kg}$ weight loss at 6 months v. $0.06 \mathrm{~kg}$ for a $418 \mathrm{~kJ}$ ( $100 \mathrm{kcal})$ reduction in solid energy.

The association between beverage consumption and obesity has been questioned ${ }^{(12)}$. However, much of the data for these studies come from people consuming liquid meal replacements that are generally used for weight loss ${ }^{(12,13)}$. As trying to lose weight is not a natural state for humans, these results might not be generalisable to free-living populations. Moreover, the studies were supported by the food industry, which tends to underestimate the contribution of SSB to poor health ${ }^{(14)}$.

Food availability has been shown to be correlated with individual intake in households and schools ${ }^{(15,16)}$. This is consistent with the emerging paradigm that contextual factors influence individual behaviour related to obesity, and that more available energy could lead to greater energy intake ${ }^{(17)}$.

There was more total energy available when the proportion of energy available from SSB was higher. This was larger than that explained by energy availability from SSB alone. Reducing energy from soft drinks may contribute to larger reductions in total energy available for consumption.

\section{Acknowledgements}

The present study was not supported by any funding. None of the authors had any competing interests. A.T.M. conceived the idea, participated in data analysis and wrote the paper. A.T. and F.P. collected and analysed the data, searched the literature and revised the manuscript.

\section{References}

1. Ebbeling CB, Feldman HA, Osganian SK et al. (2006) Effects of decreasing sugar-sweetened beverage consumption on body weight in adolescents: a randomized, controlled pilot study. Pediatrics 117, 673-680.
2. Ludwig DS, Peterson KE \& Gortmaker SL (2001) Relation between consumption of sugar-sweetened drinks and childhood obesity: a prospective, observational analysis. Lancet 357, 505-508.

3. Schulze MB, Manson JE, Ludwig DS et al. (2004) Sugarsweetened beverages, weight gain, and incidence of type 2 diabetes in young and middle-aged women. JAMA $\mathbf{2 9 2}$, 927-934.

4. Brownell KD \& Frieden TR (2009) Ounces of prevention the public policy case for taxes on sugared beverages. $N$ Engl J Med 360, 1805-1808.

5. Harnack L, Stang J \& Story M (1999) Soft drink consumption among US children and adolescents: nutritional consequences. J Am Diet Assoc 99, 436-441.

6. Leahy KE, Birch LL \& Rolls BJ (2008) Reducing the energy density of multiple meals decreases the energy intake of preschool-age children. Am J Clin Nutr 88, 1459-1468.

7. Statistics Canada (2009) About CANSIM. http://www.statcan. gc.ca/ads-annonces/cansimii/index-eng.htm (accessed April 2010).

8. Bowman SA \& Vinyard BT (2004) Fast food consumption of US adults: impact on energy and nutrient intakes and overweight status. J Am Coll Nutr 23, 163-168.

9. DiMeglio DP \& Mattes RD (2000) Liquid versus solid carbohydrate: effects on food intake and body weight. Int J Obes Relat Metab Disord 24, 794-800.

10. Malik VS, Schulze MB \& Hu FB (2006) Intake of sugarsweetened beverages and weight gain: a systematic review. Am J Clin Nutr 84, 274-288.

11. Chen L, Appel LJ, Loria C et al. (2009) Reduction in consumption of sugar-sweetened beverages is associated with weight loss: the PREMIER trial. Am J Clin Nutr 89, 1299-1306.

12. Drewnowski A \& Bellisle F (2007) Liquid calories, sugar, and body weight. Am J Clin Nutr 85, 651-661.

13. Heymsfield SB, van Mierlo CA, van der Knaap HC et al. (2003) Weight management using a meal replacement strategy: meta and pooling analysis from six studies. Int $J$ Obes Relat Metab Disord 27, 537-549.

14. Vartanian LR, Schwartz MB \& Brownell KD (2007) Effects of soft drink consumption on nutrition and health: a systematic review and meta-analysis. Am J Public Health 97, 667-675.

15. Fernandes MM (2008) The effect of soft drink availability in elementary schools on consumption. J Am Diet Assoc 108, $1445-1452$.

16. Naska A, Oikonomou E, Trichopoulou A et al. (2007) Estimations of daily energy and nutrient availability based on nationally representative household budget survey data. The Data Food Networking (DAFNE) project. Public Health Nutr 10, 1422-1429.

17. Kumanyika SK, Obarzanek E, Stettler N et al. (2008) Population-based prevention of obesity: the need for comprehensive promotion of healthful eating, physical activity, and energy balance: a scientific statement from American Heart Association Council on Epidemiology and Prevention, Interdisciplinary Committee for Prevention (formerly the Expert Panel on Population and Prevention Science). Circulation 118, 428-464. 